\title{
The democratic role of social media in political debates: The use of Twitter in the first televised US presidential debate of 2016
}

\section{Craig T. Robertson, William H. Dutton, Robert Ackland \& Tai-Quan Peng}

To cite this article: Craig T. Robertson, William H. Dutton, Robert Ackland \& Tai-Quan Peng (2019) The democratic role of social media in political debates: The use of Twitter in the first televised US presidential debate of 2016, Journal of Information Technology \& Politics, 16:2, 105-118, DOI: $10.1080 / 19331681.2019 .1590283$

To link to this article: https://doi.org/10.1080/19331681.2019.1590283

View supplementary material $\Longleftarrow$

Published online: 23 Mar 2019.

Submit your article to this journal $\widetilde{ }$

山 Article views: 191

Q View related articles $\sqsubset$

View Crossmark data 


\title{
The democratic role of social media in political debates: The use of Twitter in the first televised US presidential debate of 2016
}

\author{
Craig T. Robertson (1), William H. Dutton, Robert Ackland 이, and Tai-Quan Peng
}

\section{ABSTRACT}

Live social media commentary increasingly accompanies televised political debates. This study examines the democratic role of live Twitter commentary by analyzing a sample of tweets published during the first 2016 presidential debate between Trump and Clinton. The practices of live commenters - including joke-sharing and fact-checking - are assessed in light of six perspectives on the democratic utility of such commentary. Results show that while Twitter commentary was predominantly humorous and driven by negativity towards the candidates, a sizeable proportion of users actively engaged in practices of alternative interpretation, critique, and correction, seeking democratic accountability.

\section{KEYWORDS}

Political participation; live commentary; social media; Twitter; political debates; democracy; Fifth Estate

\section{Introduction}

The first 2016 televised debate between Donald Trump and Hillary Clinton was held on September 26, 2016. It was the most-watched in American history, viewed by 84 million people (Kennedy, 2016). This was the first of three live, televised debates between these presidential candidates, which follows an ongoing tradition of American presidential elections since the first Kennedy-Nixon debates were televised in 1960. It was also the most tweeted presidential debate at that time (White, 2016).

This study focuses on the role of live debate commentary on Twitter. In particular, it addresses a question raised about this form of political participation: What democratic value or role, if any, does it serve? To address this, our study considers the communication practices employed by those engaged in live debate commentary in light of six perspectives on its democratic utility. By analyzing what individuals say on Twitter while watching debates and the potential purposes for which they say it, we can begin to understand the overall democratic function or functions of this discourse, adding to our overall understanding of what live commentary is and the role it plays in the political ecosystem.
An analysis of a random sample of 5,000 tweets posted during the first presidential debate in 2016 serves as a unique case study. While findings regarding the democratic role of live Twitter commentary are limited to this case, the paper does seek to generate a more general set of theoretical perspectives for understanding live commentary that can provide a foundation for other cases.

\section{Twitter and live commentary}

Social media platforms such as Twitter are often used by thousands of people to comment on and discuss debates in real time. Live tweeting refers to the act of individuals watching a live event being screened on television (or online) and commenting on it using social media, such as Twitter (Houston, McKinney, Hawthorne, \& Spialek, 2013). While often seen during live broadcasts of entertainment television, the practice also has become a common accompaniment to live political debate broadcasts. It has been spurred by the affordances of Twitter, which allow for collective, interconnected, and synchronous commentary (Houston et al., 2013). Users are able to navigate through and sort streams of information, express their own views, read the views of others, and interact - all in real time.

CONTACT Craig T. Robertson robe1013@msu.edu Quello Center, College of Communication Arts and Sciences, Michigan State University, 404 Wilson Rd, East, Lansing, Ml 48824 


\section{The communication practices of live debate commenters}

While using social media to comment live on political debate broadcasts, users engage in a number of communication practices which may be of interest when considering the democratic role of such commentary. In particular, Twitter allows people to engage in conversation, selfexpression and information-sharing (Dann, 2010; Giglietto \& Selva, 2014). In the debate context, scholars have observed users engaging in discussion, play-by-play commentary, critique, and joke sharing (Ampofo, Anstead, \& O'Loughlin, 2011; Anstead \& O'Loughlin, 2011; Freelon \& Karpf, 2015). Ampofo et al. (2011) observed how tweeters performed a type of educational function by bringing in additional information, establishing different narratives than the mainstream media. Mascaro and Goggins (2015), in their study of a Republican Party primary debate, also noted how users shared additional information (via links) and attempted to engage with both the candidates and the moderator through the use of the @username function. Coddington, Molyneux, and Lawrence (2014), analyzing the practices of journalists on Twitter in the context of the 2012 presidential debates, looked at the occurrence of direct quotation of candidate statements or claims (stenography), the presence of fact-checking (references to external evidence), and other forms of discourse, such as opinion and humor.

In terms of motivations, Chadwick, O'Loughlin, and Vaccari (2017) have observed that individuals comment live on debates out of varying desires to acquire (political) information, share information and opinions with others, and to influence others. Other motivations include political interest, partisan zeal, or a desire to commune with politically like-minded others and gain ideological reinforcement (Houston et al., 2013; Thorson, Hawthorne, Swasy, \& McKinney, 2015). Users may also wish to be part of an event of national importance (Thorson et al., 2015). Lastly, with the widespread heckling and sharing of jokes on Twitter during debates, the literature suggests enjoyment is another important motivation (Freelon \& Karpf, 2015).

\section{The democratic potential of live commentary during televised debates}

The live commentary practices identified above can be related to six perspectives on the democratic role of social media users during political debates. We arrived at these six perspectives through a consideration of existing literature on live debate commentary, an exploration of the tweets we sampled, and a consideration of relevant theoretical literature. The perspectives are tied together by their common focus on social media affordances (Bucher \& Helmond, 2018), specifically not only on what platforms such as Twitter allow or afford people to do in the context of political debates, but actual behavior, which often varies widely from perceived affordances. The perspectives are distinct, though remain overlapping in certain respects, as can be seen in Table 1 .

Giglietto and Selva (2014) conducted a similar study, employing a typology in the analysis of tweets about Italian political talk-shows which drew on a uses and gratifications framework. Their typology was based on distinctions between the form of expression (subjective or objective), whether tweets were about oneself or the program, and the target of expressions (politicians, hosts, etc.). Thus, the focus of their study was on what users appeared to be attempting to get out of realtime participation. While conceptually similar to the present study, it was not framed in terms of the democratic role or function of different live tweeting practices, but rather on user gratifications.

\section{Fandom/audiencing}

People may be debate viewers and live commenters without necessarily being interested in a particular candidate, party, policy issue, or even the outcome of the election. Indeed, when it comes to the first televised debated between Trump and Clinton, it is likely that a sizeable portion of the audience tuned in for the spectacle alone, given two historic candidacies and a contentious campaign (Stetler, 2016). From this perspective, social media platforms enable individuals to commune with others as fans of the debate. This is distinct 
Table 1. Perspectives on the (Democratic) role of social media users during televised debates.

\begin{tabular}{|c|c|c|c|}
\hline Role of Users & Description & Relevant live commentary practices & $\begin{array}{l}\text { Number of tweets } \\
\text { (out of } 5,000)^{*}\end{array}$ \\
\hline Fandom, audiencing & $\begin{array}{l}\text { Social media enabling users to express themselves as } \\
\text { fans of the debate }\end{array}$ & Jokes, stenography & 2,000 \\
\hline Partisan supporters & $\begin{array}{l}\text { Enabling individuals to support parties, candidates, or } \\
\text { movements }\end{array}$ & Positive comments about Trump or Clinton & 595 \\
\hline Detractors & $\begin{array}{l}\text { Social media empowering negative outbursts, enabling } \\
\text { mobs }\end{array}$ & $\begin{array}{l}\text { Negative comments about Trump or Clinton, } \\
\text { insults }\end{array}$ & 1,774 \\
\hline Public Sphere & $\begin{array}{l}\text { Social media providing a place to assemble and } \\
\text { a platform for discussion/deliberation }\end{array}$ & User discussion & Unknown $^{+}$ \\
\hline Viewertariat & $\begin{array}{l}\text { Social media providing viewers with an enhanced, } \\
\text { interactive experience }\end{array}$ & $\begin{array}{l}\text { Directed tweets, horse race coverage, fact- } \\
\text { checking or added information }\end{array}$ & 1,282 \\
\hline Fifth Estate & $\begin{array}{l}\text { Social media empowering users to hold the press and } \\
\text { politicians more socially accountable }\end{array}$ & $\begin{array}{l}\text { Fact-checking or added information, debate } \\
\text { moderation }\end{array}$ & 900 \\
\hline
\end{tabular}

from people who are politically interested and motivated to watch because they want to support a particular candidate, for example. Highfield, Harrington, and Bruns (2013) view such live commenters as fandoms engaged in the practice of 'audiencing': "the public performance of belonging to the distributed audience for a shared media event" (p. 336). Wood and Baughman (2012), studying live commentary practices of those watching entertainment television, observed how social media platforms enabled users to express their own interpretations of the text and, alongside like-minded others, create a collective experience which culminated in the formulation of alternative narratives about it. Wohn and $\mathrm{Na}$ (2011) similarly see live tweeting as a form of self-expression and desire to be part of a collective.

In the context of debates, these forms of selfexpression and collective experience may manifest in the form of shared jokes, narratives, and the highlighting of key moments or quotations. An analysis of fandom discourse can, according to Highfield et al. (2013), highlight "the resonance of specific developments during the broadcast amongst its social media audience" (p. 335). But such fandom discourse may be of little consequence for democracy if it does not raise substantive critiques or if alternative narratives fail to either challenge or undermine dominant media interpretations of the debate. Nevertheless, individuals may learn more from debates in the process of live- tweeting by becoming more engaged and seeing relevant content and opinions from others (Houston et al., 2013).

\section{Partisan supporters}

Another perspective sees live commentary as being part of partisan self-reinforcement. Research indicates that partisans seek out information from like-minded sources (Iyengar \& Hahn, 2009) and that Twitter users have homogenous networks (Colleoni, Rozza, \& Arvidsson, 2014), reflecting a tendency toward homophily in social networks (McPherson, Smith-Lovin, \& Cook, 2001). Thus, internet users have a tendency to seek out reinforcement (Garrett, 2009). Social media spaces enable such practices.

When it comes to debates, those who watch tend to be partisan voters rather than undecideds, reflecting the role that political interest plays (Kenski \& Hall Jamieson, 2011). Partisan supporters are individuals who watch debates because of their interest in politics (in contrast to those who may which to view the spectacle) and out of a desire to support their candidate. These are individuals often watch debates through partisan lenses and have their preconceptions reinforced by viewing (Mullinix, 2015). Thus, social media commentary can be seen as a way for partisans to support individual candidates, parties, or issues, such as through coordinated online campaigning or efforts to spin the debate in real time to favor 
their candidate, and to commune with likeminded others to reinforce their views. In contrast to an open-minded discussion, partisans are motivated to cluster and express support for their predetermined positions or candidates. In the context of live debate commentary, this partisanship may be seen in expressions of partisan support and horse race coverage focused on individuals' favored candidate. Partisan supporters are distinct because they are focused on reinforcement - the cheering-on and support of candidates. The democratic role of live commentary here lies with the affordances provided to individuals to express their opinions, support their candidates and network with other partisans.

\section{Detractors}

At the same time, live commentary can be distinctly negative and even vitriolic. Some research has shown political talk on social media to be "relentlessly negative" (Pew Research Center, 2012 , p. 27). Such sentiment may be targeted at elites during protest, with social media affording coordination (Bonilla \& Rosa, 2015). Users may also engage in public shaming (Kasra, 2017). In this view, live commenters can be seen as 'detractors' or even as virtual mobs denigrating one participant or all. Here, live commenters are detractors in the sense that they are speaking ill of, finding fault in, or criticizing (fairly or not) candidates. To the degree that this is coordinated or taking place en masse and to the extent that such discourse may be disparaging, detractors may also be seen as virtual mobs.

Partisans are distinguished by the fact their discourse is focused supporting one or another candidate or side in the debate. In contrast, detractors or the virtual mob express opposition to or criticisms of one or all candidates (or even the moderator), making it necessary to assess this discourse apart from positive, supportive discourse. The role of live commentary here may be considered democratic given that individuals have the right to gather and express opposition. On the other hand, negativity may be unconstructive, at least insofar as users are simply denigrating or abusing candidates. In the context of debate commentary, this negativity may manifest itself as insults or attacks.

\section{Public sphere}

The most idealistic democratic perspective sees social media platforms as deliberative spaces or potential public spheres (Halpern \& Gibbs, 2013). Here we draw from scholarship which notes the potential of the internet to enhance civic engagement (Dahlgren, 2005). Kirk and Schill (2011) argue that social media, due to their affordances, invoke participatory, deliberative spaces where civic engagement can be fostered outside of a debate, bringing people together in a type of 'digital agora'. Social media platforms may be seen as potential public spheres because their architecture and technological affordances open up the opportunity for deliberation (Kirk \& Schill, 2011). We treat the public sphere as a distinct perspective precisely because its focus is deliberation. However, the concept of the public sphere has been criticized, primarily because it is seldom approached in practice. There has also been criticism of the potential for the online public sphere, even if it were realized in practice, to exclude or marginalize certain voices (Dahlberg, 2001). Nevertheless, the opportunity for deliberative discussion remains and thus there is democratic potential. In the context of debate commentary, we see the public sphere as likely to manifest in direct discussion between Twitter users.

\section{Viewertariat}

Live commenters have also been conceptualized as a 'viewertariat', which is related to the public sphere perspective, though distinct from it. It speaks to individuals using social media to enhance their otherwise more limited viewing and participative experience. This perspective draws on prior research and is, as such, one rooted in empirical observations of live commentary practices. Anstead and O'Loughlin (2011) define the viewertariat as "viewers who use online publishing platforms and social tools to interpret, publicly comment on, and debate a television broadcast while they are watching it [live]" (p. 
441). It is again focused on social media affordances, though on opportunities for interpretation, commentary and debate, rather than deliberation per se.

What differentiates the viewertariat perspective is its focus on a number of unique live commentary practices arising from digital affordances. For instance, Anstead and O'Loughlin (2011) observed in their political debate study how members of the viewertariat expressed collective identities and made calls to action, utilizing Twitter as a tool for political influence. Ampofo et al. (2011), in their study of the 2010 UK General Election leaders' debate, observed interaction between ordinary users, with information being added by users to help supplement the broadcast and clarify questions being asked. They also saw users addressing elites, attempting to challenge their views and interpretations. These two studies suggest that the democratic role of viewertariat practices lay with the unique opportunity afforded to individuals to add additional information to the discussion, make calls to action, address or challenge elites and, by proffering counter narratives, influence the interpretive framing of events.

\section{The Fifth Estate}

Lastly, the democratic role of live commentary during debates can be viewed through the lens of the Fifth Estate. This perspective views members of the online public as networked individuals enabled by the affordances of the internet to communicate with one another, organize, as well as source, share and publish information, in ways which may challenge and promote the accountability of institutions such as the government, politicians, and the press (Dutton, 2009, 2015). The Fifth Estate is an extension of the concept of the Fourth Estate, whereby the press is empowered by its reach and resources to hold institutions to account. However, the Fifth Estate differs from the Fourth in the way that its functions are dispersed among a wider array of individuals beyond professional journalists and the fact that the press is also a target of public accountability.

While the viewertariat perspective, in some regards, may implicitly be focused on accountability, with members of the online public making calls to action and developing counter narratives which may influence the press and politicians, the Fifth Estate makes the link between live commenters and their potential role as sources of democratic accountability explicit. This is what makes the Fifth Estate distinct from the viewertariat. In the context of live debate commentary, the Fifth Estate may operate in such a way that networked individuals on Twitter are able to enhance their communicative power and draw attention to particular issues or aspects of the debate which may be overlooked or dismissed by the mainstream media. At the same time, individuals may play a role in holding the media (or debate moderator) to account by critiquing their practices, or raising important arguments geared at promoting institutional accountability. People may also factcheck the statements of politicians or criticize them for the lack of clarity or substance in their answers to questions.

In light of this overview of perspectives on the democratic utility or role of live social media commentary during political debates, it must be asked: What perspectives are best reflected in debate commentary?

\section{Methodology}

The present study takes a mixed methods approach, employing qualitative and quantitative analyses, centered on a content analysis of tweets posted before, during, and after the first presidential debate between Donald Trump and Hillary Clinton on September 26, 2016. Its aim is to more fully describe live commentary practices and identify the democratic value of live commentary, as seen through particular perspectives. This study quantifies the use of eight live commentary practices in a sample of tweets and then assesses how they map onto six perspectives regarding the democratic role of live commentary (see Table 1). These perspectives are both distinct yet overlapping. As such, it is necessary to both quantitatively and qualitatively explore the live commentary practices of individuals, paying attention to themes in discourse as well.

\section{Sampling}

The Twitter Firehose was used to collect all tweets (including retweets) containing at least one of eight hashtags (\#DebateNight, \#Debates, 
\#Debates2016, \#Election2016, \#HillaryClinton, \#Hillary2016, \#DonaldTrump, \#Trump2016), ${ }^{1}$ selected because they were the most popular tags being used on the platform to discuss the debate. Tweets were collected from between fifteen minutes before the scheduled start of the debate until fifteen minutes after its scheduled end. The collection was conducted shortly after the debate, using the historical search feature of the Twitter Firehose API. Tweets were not collected live because of uncertainty about the volume of tweets and potential for server overload. This process resulted in the collection of 118,118 pre-debate tweets, 5,477,373 duringdebate tweets, and 979,026 post-debate tweets $(6,574,517$ tweets total). Original tweets were then identified by excluding all retweets; filtering out retweets reduced the total number of tweets to 2,675,352 (a reduction of around 60\%).

We then drew a systematic random sample of 5,000 tweets from this set of 2.6 million. The $2,675,352$ unique tweets were distributed across the data collection hashtags as follows: \#DebateNight (N = 1,737,005), \#Debates (1,119,638), \#Debates2016 $(546,837)$, \#Election2016 (7,401), \#HillaryClinton (30,384), \#Hillary2016 (4,455), \#DonaldTrump $(27,971)$, and \#Trump2016 (6,783). Some tweets used multiple hashtags. Systematic random sampling was used to ensure that a proportionate number of tweets were included from periods of high activity during the debate (tweets were ordered by time).

\section{Classifying content}

Tweets were classified into eight types of live commentary practices following an original coding scheme developed for this study. Coding (by a researcher and undergraduate coder) was not conducted in real-time. After the sample of tweets was drawn, coders matched timestamps on the tweets with the timestamp in the debate transcript. Development of the classification scheme was conducted using both an inductive and deductive approach, drawing on both quantitative and qualitative traditions. Taking guidance from prior research and an inductive exploration of tweets, we arrived at a list of eight common practices:

1. Humor/jokes: tweets which made an attempt at a joke or at expressing humor (Krippendorff's $a=0.73)$. 2. Stenography: tweets which consisted wholly or partially of quotations from the debate $(\alpha=0.72)$. 3. Directed tweets: tweets which used the @username function to address specific people. Since directed Tweets were defined as any tweets incorporating @username function, intercoder reliability for this variable was not calculated. 4 . Fact-checking/added content: tweets which either attempted to fact-check what was said or which add additional information $(\alpha=0.88)$. 5. Debate moderation: tweets which spoke to the operation of the debate in terms of how it was being run. Tweets in the style of debate moderation included content policing the rules of the debate $(\alpha=0.77)$. 6. Candidate valence: tweets which either explicitly expressed support for or opposition to a named candidate (from 'more negative' to 'more positive'). Two categories were created for both Donald Trump and Hillary Clinton (Trump: $a=0.76$. Clinton: $a=0.78)$. 7. Horse race coverage: tweets which focused on who was winning or losing the debate $(\alpha=0.86) .8$. Candidate insults: tweets which denigrated, disrespected, or abused the candidates, going beyond negative sentiment to more uncivil discourse $(\alpha=0.64)$.

Regarding user discussion, given our method of only collecting tweets which featured at least one of our eight target debate-related hashtags, we were not able to capture user discussions where these hashtags were not present. Tweets were coded for the presence/absence of all eight concepts so that interrelationships between different types of practices could be assessed (i.e. tweets which were humorous but which also contained a fact-check). Quantitative methods were employed to aid in the reliable classification of tweets for additional qualitative analysis, which then proceeded on the basis of identifying themes among related tweets.

\section{Analysis}

The following sections address the frequency of live commentary practices and how such practices map onto each of the six perspectives on the democratic role of such commentary. The number of tweets of each type posted throughout the debate are broken down in Table 2. It shows that 


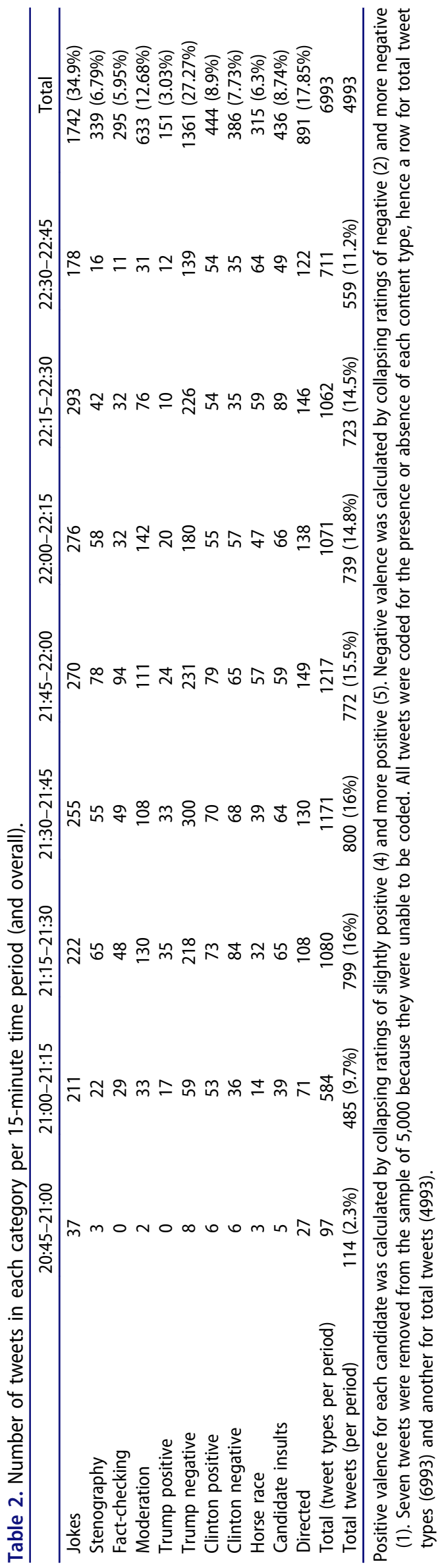

jokes were the most common type of tweet, followed by negative tweets about Donald Trump.

The following sections address each live commentary practice and the perspective(s) they relate to. As we have noted, there is not a one-to-one relationship between practices and democratic perspectives. A given practice may support more than one perspective, making our qualitative analysis of each tweet and the co-occurrence of practices critical to the study.

\section{Candidate sentiment}

Negative tweets about Trump were the most common in our sample, followed by positive tweets about Clinton. Numbers for candidate valence were in some instances low because the majority of tweets were either judgmentally neutral or did not mention the candidates explicitly (Trump neutral or not mentioned $=3474$ tweets, Clinton neutral or not mentioned $=4156$ tweets). The fact that much live commentary on Twitter was driven by negativity has been noted about social media discourse generally (Pew Research Center, 2012). However, Trump was the main target of this negativity. The level of negativity particularly towards Trump points to the presence of a large contingent of anti-Trump detractors and runs against findings that Twitter was actively proTrump during the debate (see Kollanyi, Howard, \& Woolley, 2016). In contrast, pro-Trump content in this study was found to be proportionately small. We highlight alternative explanations for this finding in an online appendix which specifically addresses the question of Twitter bots. Meanwhile, the fact that positive Clinton tweets outweighed the negative suggests the presence of a larger contingent of liberal partisans. Negative tweets about Clinton did not lag far behind in number, however.

While tweets about the candidates were negative, such commentary was not without direction. Many had substantive critiques to make: a fifth (21\%) of negative Trump tweets contained factchecks or debate moderation notes, while almost a quarter (24\%) of negative Clinton tweets did too, supporting a Fifth Estate perspective.

\section{Humor/jokes}

In terms of jokes or attempts at humor, 34.9 percent of tweets were categorized as such. More 
jokes $(25 \%$ of them) were negative towards Trump, with few being either positive or negative towards Clinton (8.4\%). Live commenters used jokes to deride the candidate they did not like, supporting a detractor perspective. However, the majority of jokes were not negative (or positive) towards the candidates but judgmentally neutral. In this light, it can be said that live commenters used Twitter as a platform for self-expression, with jokes corresponding to the practice of audiencing. Users joked to let off steam and be a part of a significant political spectacle - being a debate fandom.

Freelon and Karpf (2015) have argued the value of studying humor an example of genre-blending by hybrid audiences who bring their own unique forms of critique to bear on important political events. In their study, they found that many jokes "made substantive political points" (p. 402), acting as pointed political criticism or satire. In this view, seeing humor as a form of substantive critique, a small portion of jokes did contain some substantive criticisms of the candidates and moderator, often framed satirically or sarcastically. Fully 7.7 percent of jokes contained factchecks or debate moderation. The latter tweets were largely tongue-in-cheek commentaries focused on the lack of control moderator Lester Holt appeared to have over the debate, for example: "This Trump guy is a pretty good moderator of the debate", "Wow, Lester Holt is still there? I thought maybe he'd left to get coffee and a donut", and "Lester Holt is the worst substitute teacher ever."

Meanwhile, negative, critical jokes were predominantly directed at Trump, with users noting his interruptions, the lack of specifics or coherence provided in his responses, and his tendency to avoid directly answering questions, for example: "Trump on his tax returns is like dealing with a seventh grader on their homework - where is it? I CAN'T SHOW IT TO YOU!" and "Trump: Lester, I'm really happy for you. I'll let you finish, but I'm gonna avoid directly answering this question right now." Thus, while many jokes were made for their own sake, with viewers acting as a fandom, in a variety of ways, some tweets expressed a desire for accountability from candidates and the moderator. Moreover, live tweeters focused on confounding elements of the debate, making frank assessments of what they were viewing, thereby providing a particular narrative for the debate and acting as a viewertariat.

\section{Stenography}

When it came to stenography, the overwhelming majority of commentary tweets which consisted either wholly or partially of quotations from the debate were quotes from Donald Trump (59.8\%). Only a third of quotations were from Hillary Clinton (35.8\%) and 4.4 percent from moderator Lester Holt. The majority of these tweets included additional commentary alongside the quotation, with 71 percent including jokes, positive or negative candidate sentiment, and other frames. A large portion of quotations from Trump were negatively framed, supporting the detractor perspective. For example, a preponderance of tweets negatively reacted to Trump's "that's called business, by the way" remark, which came in response to a claim by Clinton that he rooted for the housing crisis and made money from it. The most emphasized quotes in our sample were comments by Trump about his comparative "temperament" and "stamina", which came at the end of the debate. Such comments generated many strong negative responses from live tweeters, with individuals questioning his choice of words. Meanwhile, commentary focused on Hillary Clinton's statements tended to be positive (supporting the partisan perspective). These tweets focused largely on a one-liner from Clinton about Trump's policy being "Trumped up trickle-down" economics and Clinton's response to Trump questioning of her support for the TPP trade deal, to which she retorted: "Well, Donald, I know you live in your own reality."

Wood and Baughman (2012) note that live commenters oftentimes create their own narratives and interpret the text in their own ways, resulting in potentially new understandings. Here, viewers were engaging in a process of interpretation, highlighting key quotes they felt represented the competence of each debater. In particular, live commenters focused on quotes from Donald Trump which in their minds raised questions about his fitness for office. As such, live commenters could be said to have operated as a viewertariat drawing attention to a key narrative about candidate competency. 


\section{Horse race coverage}

Journalists often treat campaigns and debates as horse races, with coverage focused on who is winning or losing (Pew Research Center, 2012). In this vein, it was thought that live commentary may have also followed this journalistic model, with viewers tracking the debate in terms of points scored or lost. However, only a small proportion of tweets overall $(6.3 \%)$ treated the debate as a horse race. Live commenters, for example, noted that "Trump looks strong, smart, decisive.. He will win in landslide" and " 20 minutes in and \#Trump is performing better by far." Of the horse race tweets, 59 were negative towards Trump and 35 positive towards him. Meanwhile, 21 were negative towards Clinton and 88 positive towards her. Such small numbers indicate that live commenters were more concerned with the substance of what the candidates were saying, rather than being directly concerned with following who was "winning" at any one moment (detracting from a viewertariat perspective).

\section{Insults}

A suggested requirement for constructive political deliberation and dialogue is civil discourse (Papacharissi, 2004). In this view, political talk must be rational and well-argued, not falling into illogical or unreasoned debate, in order for such talk to be useful for enhancing democratic processes. In order to gauge the level of uncivil discourse - and a certain level of mob-like behavior insults were coded for. Insults are distinguished from negative discourse insofar as these tweets do not express substantive criticisms or veer into personal attacks and derogatory language, for example: "Of course Hillary wears red cause she's the devil", "Trump sounds like a town drunk", "Hillary's head is bigger than the rest of her body", and "The hamster wheel in Trump's head is spinning out of control."

Few tweets overall (8.7\%) were classified as being insulting towards the candidates. The bulk of these were negative towards Donald Trump or were classified as attempts at humor. They contained attacks on his appearance, character, and perceived competence. Comparatively fewer insults were negative towards
Hillary Clinton, with these negative tweets focused similarly on her appearance and character. While many of the tweets in this category were offensive, they were surprisingly few in number overall. Thus, live commentary during the debate was not so lacking in civility as to be interpreted as widespread abuse, detracting somewhat from the idea of a virtual mob.

\section{Directed tweets}

One limitation of the data collection method used here was that any conversations between users, absent the use of debate-related hashtags, were not included. This limits any focus on social media discussions or deliberations during the debate. Nevertheless, prior studies have found limited evidence of conversation in live commentary (Anstead \& O'Loughlin, 2011; Mascaro \& Goggins, 2015). Based on this research, it appears that live commentary may largely consist of expressions of opinion, with discussion or debate not being the norm. Such an observation detracts from the public sphere perspective.

Despite data limitations, the question of who live commenters wished to address during the debate can be assessed. Overall, 17.85 percent of tweets employed the @username function. Of the 892 directed tweets, 38 percent were directed at @realDonaldTrump, being largely negative. Meanwhile, 25 percent spoke to @HillaryClinton. Sentiment here was a mix of positivity and negativity, though positive tweets did outweigh negative tweets.

Qualitatively assessing these tweets, it was noted that users were not necessarily using the @username function to engage in discussion but were using this feature to address candidates as an imagined audience (Marwick \& Boyd, 2011). For example, tweets asked, "Yo @realDonaldTrump list five things about America that you actually like", and "Who does your fact checking @HillaryClinton? The same people that did all your deleting?" The @username function was a way for users to engage in simulated dialogue with the candidates. Of these tweets, 17 percent contained either fact-checks or debate moderation points, with tweets directed at Trump, for example, asking him to stop interrupting the debate or calling for him to more comprehensively answer 
a question. In this way, viewers acted as an accountability check on Trump (supporting the Fifth Estate perspective). By challenging elites, users were also acting as the Fifth Estate as well as a viewertariat.

\section{Fact-checking/additional information}

Only 5.9 percent of live commentary tweets posted during the debate were classified as factchecks or content added by viewers to supplement the debate. Despite this, many of these tweets provided useful information which added background to candidate statements.

The preponderance of the fact-checks provided by users supported claims made by Hillary Clinton during the debate. For instance, Trump denied to Clinton that he had said pregnancy was an inconvenience - a claim that was fact-checked by live tweeters. Trump also denied to Clinton that he said climate change was a hoax, a claim which was refuted by a resurfaced tweet from 2012 . A large proportion of fact-check tweets also bolstered moderator Lester Holt's checks on Trump. Holt provided three direct fact-checks during the debate, all to counter statements made by Trump. One related to the constitutionality of 'stop and frisk', a policy Trump said he supported. Holt noted that the policy was ruled unconstitutional and a number of tweets backed this up. Additionally, Holt fact-checked Trump on his past support for the invasion of Iraq. Again, a number of live tweeters backed up Holt, providing links to news articles. Beyond this, there was additional content added by viewers which was not mentioned by the participants. Such content included information about the Clinton Foundation, Bill Clinton's record as president, and Trump's business practices.

Overall, tweets of this type operated as accountability checks, predominantly on Donald Trump, with users acting as a Fifth Estate. The addition of new content to the debate by users also complements the Fifth Estate and the viewertariat perspectives, with users bringing other issues into the purview of the debate, raising particular questions about Trump and Clinton's past actions.

\section{Debate moderation}

In total, 12.7 percent of tweets posted by live commenters spoke to debate moderation - one of the largest categories. At least a quarter of these were complaints made by viewers about the lack of control moderator Lester Holt appeared to have over the debate, with live tweeters noting constant interruptions particularly from Donald Trump. For example, viewers complained: "I feel like the debate rules are not being followed. Also, where's Lester?" and "LESTER! Wake up! You're supposed to be Moderating!" Tweets in this category also complained of the candidates not properly answering questions posed or not being clear in their responses. Live tweeters called for followup questions from Lester Holt using the @username function. Further, Twitter users argued that issues of real importance to voters were not being discussed, for example: "HOW ABOUT WE DEBATE THE REAL ISSUES INSTEAD OF TAX RETURNS AND EMAILS" and "here goes @LesterHoltNBC w the \#birtherism Cuz AGAIN that's on the list of what's important to Americans..." These viewers wanted less time spent on issues they saw as peripheral or unimportant. In these ways, live commenters sought to hold debate participants to account for perceived failings, supporting the Fifth Estate perspective.

\section{Discussion}

This study sought to identify what live commentary practices were reflected in a sample of tweets from the first presidential debate of 2016 live debate commentary and, based on the prevalence of such practices, what could be said about the democratic roles of such commentary. Overall, it is observed that none of the indicators alone constituted a majority of tweets. Jokes were the most common type of tweet, being a third of the coded content, followed by negative Trump tweets, directed tweets and debate moderation tweets. Combining relevant indicators of the perspectives (Table 1), fandom/audiencing saw the most tweets (2,000 tweets in the sample), with the detractor $(1,774)$, viewertariat $(1,282)$, Fifth Estate (900), and partisan supporter perspectives (595), respectively, following. In light of this, it can be said that 
live commentary, in this context, was a mix of derisive and humorous observations. Live commentary was, therefore, a means for selfexpression, with Twitter users perhaps motivated by a desire to be part of a collective experience (Thorson et al., 2015). Sharing jokes and negative sentiments may have been a way for people to be part of a nationally-important event and have their personal opinions heard.

In terms of the democratic role of this type of commentary, it must be noted that within liberal democratic systems political participation and engagement are generally valued (though some scholars have raised concerns over the effects of negative expressions on political polarization; see Hwang, Kim, \& Huh, 2014). Moreover, it has been found that individuals who live-tweet debates learn more, pointing to the benefit of this type of political engagement (Houston et al., 2013). Learning may arise from the fact that live commenters are more engaged, which promotes elaborative processing (Houston et al., 2013), or from the fact that viewers who are also tracking the debate on Twitter may be exposed to more additional information, including fact-checks from other users.

However, beyond this, fandom and detractor discourse may be seen to be of little consequence if it does not raise substantive critiques or otherwise influence the interpretive framing of the debate. On this point, it can be noted that a second, related function of live commentary was in providing substantive criticisms of the candidates and the debate process. Negative tweets, jokes, stenography tweets, and directed tweets all, too some degree, contained critiques which spoke to viewer desire for accountability. A sizeable number of tweets also made debate moderation points, calling on candidates to provide clearer answers and the moderator to take better control of the debate. As such, the negativity of live commenters was not aimless, but did often focus on real and substantive issues viewers had with both the candidates and the moderator. Even while critiques of candidate image or perceived characteristics were put forward, these remained, for the public, relevant criticisms of individuals running for president.
Moreover, viewers appeared to coalesce around a partisan narrative about Donald Trump, with negative attention given to his statements. Even though tweets did not tend to cover the debate as a horse race, it can be said that Trump did not fare well in the eyes of live commenters (as seen in the number of negative tweets). While this assessment accorded with most post-debate analyses by the media, the online public perhaps was more readily critical of Trump's lack of coherence or apparent competence, driving this framing home decisively. Live commenters also added small pieces of new information to the debate which framed their interpretations. Such findings support the viewertariat and Fifth Estate perspectives.

Thus, a clear democratic role of live commentary was in seeking to challenge elites and hold political actors to account. Nevertheless, there was a large portion of tweeters not engaged in these practices, with most jokes, insults and negative candidate tweets fitting into fandom and detractor perspectives. Interestingly, it appeared as though many Twitter users did not turn out to cheer-on their candidate but rather to deride one or both candidates or the moderator. Positive candidate tweets represented only a small portion of the overall sample, reflecting other observations about the negativity of social media (Pew Research Center, 2012). Likewise, our analysis did not lend support to notions of the public sphere in this context. Directed commentary largely consisted of candidate critiques or expressions of support (mostly for Clinton), framed as simulated dialogue. However, this analysis did not include replies to tweets which might yield more evidence on the existence of real dialogue during the live debates.

\section{Conclusion}

This study focused on describing the features of a unique form of political participation - live Twitter commentary - and assessing its democratic role in the political ecosystem. Generally, live tweets during the first presidential debate of 2016 were mostly of the type one might expect from social media commentary: full of humor and negativity. Yet even among these types of tweets were genuine and substantive 
criticisms representing direct, active and often partisan engagement with the debate. Commentary itself represented a desire on the part of viewers to be involved and to be heard. Users pushed for accountability from candidates and the moderator while providing their own interpretations of the debate.

Of course, the findings of this study are limited to the context of the first presidential debate of 2016 and our focus on Twitter. While jokes, insults and fact-checking were all common practices used in this case study, it may be that studies of other debates and on other platforms could uncover the use of distinctly different live commentary practices supporting different perspectives. While any case study is unique, it is possible that the first Trump vs. Clinton debate was particularly unique, given the massive public interest it engendered and the distinctiveness of the candidates. Nevertheless, the same attributes make this debate inherently significant on its own terms. Moreover, Twitter users are not representative of the American electorate. Nevertheless, Twitter is arguably one of the most open and active social media platforms in which we can systematically study real-time communication practices and their democratic role.

A further limitation of this study is the fact that we did not analyze retweets or likes, which might provide an indicator of whether live commenters were listened to by others. A lack of complete data providing insight into deliberation or discussion is another limitation. In this context, future studies may also consider who gets to speak and who gets heard in live tweeting contexts, as well as the degree to which users engage with one another. Analyzing media coverage of Twitter discourse may also be necessary to determine what impact such discourse has, if any, on debate interpretations.

Overall, despite much criticism of televised debates and the role of live commentary on social media, this study shows that they remain crucially relevant to the public as sources of information and touchstones for political conversation. If real-time public participation is both encouraged and incorporated into future debates, this may stimulate further online discussion, which may have positive ramifications for the public, for example by increasing political knowledge and fostering further political participation.

\section{Note}

1. Data were provided via Uberlink (a company that Ackland is affiliated with), possible through support from MSU's Quello Center.

\section{Funding}

This research was supported by the Quello Center at Michigan State University. It was stimulated by the work of Professsor Jay Blumler with colleagues Professor Stephen Coleman and Dr. Giles Moss on the democratic entitlements of televised debates.

\section{Notes on contributors}

Craig T. Robertson is a doctoral student at Michigan State University whose research focuses on media trust, fact-checking and new media. Specific focus is placed on the role that political ideology plays in shaping attitudes and activities in these domains.

William H. Dutton, an Emeritus Professor at University of Southern California, is a Senior Fellow at the Oxford Internet Institute and Oxford Martin Fellow at the University of Oxford.

Robert Ackland is an Associate Professor in the School of Sociology and director at the VOSON Lab at the Australian National University in Canberra, Australia.

Tai-Quan Peng is an Associate Professor at the Department of Communication, Michigan State University. He is interested in examining health communication and political communication phenomena with computational methods (e.g., text mining, network modeling, and temporal modeling).

\section{ORCID}

Craig T. Robertson (D) http://orcid.org/0000-0001-9461-8132

Robert Ackland (D) http://orcid.org/0000-0002-0008-1766

\section{References}

Ampofo, L., Anstead, N., \& O’Loughlin, B. (2011). Trust, confidence, and credibility: Citizen responses on twitter to opinion polls during the $2010 \mathrm{UK}$ general election. Information. Communication \& Society, 14(6), 850-871. doi:10.1080/1369118X.2011.587882

Anstead, N., \& O'Loughlin, B. (2011). The emerging viewertariat and $\mathrm{BBC}$ question time: Television debate and real-time commenting online. The International Journal 
of Press/Politics, 16(4), 440-462. doi:10.1177/19401612 11415519

Bonilla, Y., \& Rosa, J. (2015). \# Ferguson: Digital protest, hashtag ethnography, and the racial politics of social media in the United States. American Ethnologist, 42(1), 4-17. doi:10.1111/amet.2015.42.issue-1

Bucher, T., \& Helmond, A. (2018). The affordances of social media platforms. In J. Burgess, A. Marwick, \& T. Poell (Eds.), The SAGE handbook of social media (pp. 233-253). London: Sage Publications.

Chadwick, A., O'Loughlin, B., \& Vaccari, C. (2017). Why people dual screen political debates and why it matters for democratic engagement. Journal of Broadcasting \& Electronic Media, 61(2), 220-239. doi:10.1080/ 08838151.2017.1309415

Coddington, M., Molyneux, L., \& Lawrence, R. G. (2014). Fact checking the campaign: How political reporters use Twitter to set the record straight (or not). The International Journal of Press/Politics, 19(4), 391-409. doi:10.1177/1940161214540942

Colleoni, E., Rozza, A., \& Arvidsson, A. (2014). Echo chamber or public sphere? Predicting political orientation and measuring political homophily in Twitter using big data. Journal of Communication, 64(2), 317-332. doi:10.1111/ jcom.2014.64.issue-2

Dahlberg, L. (2001). Computer-mediated communication and the public sphere: A critical analysis. Journal of Computer-Mediated Communication, 7(1).

Dahlgren, P. (2005). The Internet, public spheres, and political communication: Dispersion and deliberation. Political Communication, 22(2), 147-162. doi:10.1080/10584 600590933160

Dann, S. (2010). Twitter content classification. First Monday, 15(12). doi:10.5210/fm.v15i12.2745

Dutton, W. H. (2009). The fifth estate emerging through the network of networks. Prometheus, 27(1), 1-15. doi:10.1080/08109020802657453

Dutton, W. H. (2015). The internet's gift to democratic governance: The fifth estate. In S. Coleman, G. Moss, \& K. Parry (Eds.), Can the media save democracy? Essays in honour of Jay G. Blumler (pp. 164-173). London, Abington: Palgrave Macmillan.

Freelon, D., \& Karpf, D. (2015). Of big birds and bayonets: Hybrid Twitter interactivity in the 2012 presidential debates. Information, Communication \& Society, 18(4), 390-406. doi:10.1080/1369118X.2014.952659

Garrett, R. K. (2009). Politically motivated reinforcement seeking: Reframing the selective exposure debate. Journal of Communication, 59(4), 676-699. doi:10.1111/ jcom.2009.59.issue-4

Giglietto, F., \& Selva, D. (2014). Second screen and participation: A content analysis on a full season dataset of tweets. Journal of Communication, 64(2), 260-277. doi:10.1111/ jcom.2014.64.issue-2

Halpern, D., \& Gibbs, J. (2013). Social media as a catalyst for online deliberation? Exploring the affordances of Facebook and YouTube for political expression. Computers in Human Behavior, 29(3), 1159-1168. doi:10.1016/j.chb.201 2.10 .008

Highfield, T., Harrington, S., \& Bruns, A. (2013). Twitter as a technology for audiencing and fandom: The \#Eurovision phenomenon. Information, Communication \& Society, 16(3), 315-339. doi:10.1080/1369118X.2012.756053

Houston, J. B., McKinney, M. S., Hawthorne, J., \& Spialek, M. L. (2013). Frequency of tweeting during presidential debates: Effect on debate attitudes and knowledge. Communication Studies, 64(5), 548-560. doi:10.1080/10510974.2013.832693

Hwang, H., Kim, Y., \& Huh, C. U. (2014). Seeing is believing: Effects of uncivil online debate on political polarization and expectations of deliberation. Journal of Broadcasting \& Electronic Media, 58(4), 621-633. doi:10.1080/0883815 1.2014 .966365

Iyengar, S., \& Hahn, K. S. (2009). Red media, blue media: Evidence of ideological selectivity in media use. Journal of Communication, 59(1), 19-39. doi:10.1111/jcom.2009.59. issue-1

Kasra, M. (2017). Vigilantism, public shaming, and social media hegemony: The role of digital-networked images in humiliation and sociopolitical control. The Communication Review, 20(3), 172-188. doi:10.1080/ 10714421.2017.1343068

Kennedy, M. (2016, September 27). Clinton-Trump showdown was the most-watched presidential debate ever. NPR. Retrieved from https://www.npr.org

Kenski, K., \& Hall Jamieson, K. (2011). Presidential and vice presidential debates in 2008: A profile of audience composition. American Behavioral Scientist, 55(3), 307-324. doi:10.1177/0002764210392166

Kirk, R., \& Schill, D. (2011). A digital agora: Citizen participation in the 2008 presidential debates. American Behavioral Scientist, 55(3), 325-347. doi:10.1177/ 0002764210392167

Kollanyi, B., Howard, P. N., \& Woolley, S. C. (2016). Bots and automation over Twitter during the first US presidential debate. Retrieved from https://ora.ox.ac.uk/

Marwick, A. E., \& Boyd, D. (2011). I tweet honestly, I tweet passionately: Twitter users, context collapse, and the imagined audience. New Media \& Society, 13(1), 114-133. doi:10.1177/1461444810365313

Mascaro, C. M., \& Goggins, S. P. (2015). Technologically mediated political discourse during a nationally televised GOP primary debate. Journal of Information Technology \& Politics, 12(3), 252-269. doi:10.1080/19331681.2015.1 071687

McPherson, M., Smith-Lovin, L., \& Cook, J. M. (2001). Birds of a feather: Homophily in social networks. Annual Review of Sociology, 27(1), 415-444. doi:10.1146/annurev. soc.27.1.415

Mullinix, K. J. (2015). Presidential debates, partisan motivations, and political interest. Presidential Studies Quarterly, 45(2), 270-288. doi:10.1111/psq.v45.2 
Papacharissi, Z. (2004). Democracy online: Civility, politeness, and the democratic potential of online political discussion groups. New Media \& Society, 6(2), 259-283. doi:10.1177/1461444804041444

Pew Research Center. (2012, November 2). Winning the media campaign 2012. Retrieved from http://www.journal ism.org

Stetler, B. (2016, September 23). 100 million? Ratings expectations for first trump-clinton debate are sky high. CNN Business. Retrieved from https://money.cnn.com

Thorson, E., Hawthorne, J., Swasy, A., \& McKinney, M. S. (2015). Co-viewing, tweeting, and Facebooking the 2012 presidential debates. Electronic News, 9(3), 195-214. doi:10.1177/1931243115593320

White, D. (2016, September 27). This was the most tweeted presidential debate ever. Time. Retrieved from http://time. com/

Wohn, D. Y., \& Na, E. K. (2011). Tweeting about TV: Sharing television viewing experiences via social media message streams. First Monday, 16(3). doi:10.5210/fm.v16i3.3368

Wood, M. M., \& Baughman, L. (2012). Glee fandom and Twitter: Something new, or more of the same old thing? Communication Studies, 63(3), 328-344. doi:10.1080/ 10510974.2012.674618 